\title{
Fostering Pre-Service Teacher Trainees’ Understanding of Membrane Transport with Interactive Computer Animations
}

\author{
Animesh K. Mohapatra \\ Regional Institute of Education (NCERT), Bhubaneswar, India \\ Email: akmrie01@yahoo.co.in
}

Received June $8^{\text {th }}$, 2013; revised July $8^{\text {th }}$, 2013; accepted July $15^{\text {th }}, 2013$

\begin{abstract}
Copyright (c) 2013 Animesh K. Mohapatra. This is an open access article distributed under the Creative Commons Attribution License, which permits unrestricted use, distribution, and reproduction in any medium, provided the original work is properly cited.
\end{abstract}

\begin{abstract}
Educators often struggle when teaching various membrane transport processes because typically they have only two-dimensional tools to teach something that plays out in four dimensions. Research has demonstrated that visualizing processes in three dimensions aids learning, and animations are effective visualization tools for learners and aid with long-term retention. The purpose of this study was to explore how far the use of computer animations in membrane transport instruction can contribute to pre-service teacher trainees' understanding of concepts and processes in membrane functions. Two comparable groups of first year pre-service teacher trainees participated: The control group (30 trainees) was taught in the traditional lecture format, while the experimental or animation group (32 trainees) received instructions which were integrated with computer animations. Four instruments were designed and used in the study: a closed form statement based questionnaire, a multiple choice questionnaire, an open ended questionnaire and personal interview. Analysis of the pre-test and post-test results showed that the experimental group had significantly higher scores than the control group. This trend was also reflected in personal interviews. This clearly indicates that computer animations have deepened the understanding of various concepts and processes of membrane transport of experimental group teacher trainees compared to that of control group. On the basis of these findings, it is concluded that animations can provide learners with explicit dynamic information that is either implicit or unavailable in static graphics. Therefore, it is recommended that the use of computer animation, a type of instructional mode which is capable of transforming students from passive receptacles of knowledge into active learners, should be used to teach Biology.
\end{abstract}

Keywords: Pre-Service Teacher Trainees; Computer Animation; Cell Membrane; Membrane Transport; Passive Transport; Active Transport; Osmosis and Diffusion

\section{Introduction}

Improving science achievement through the use of more effective instructional strategies, promoting the active role of the learner, and promoting the facilitative role of the teacher have long been an aspiration of science educators. The effective teachers use a diversity of methods and approaches to assist their students in the learning process. The common teaching methods preferred by the biology teachers are the lecture method and question-and-answer approach. In these traditional teaching methods, the teacher transmits the information and the students have been the passive recipient of information. This information could be delivered more effectively by using multimedia (Barnett et al., 1996; Ramsden, 1996; O’Hagan, 1997; Sneddon et al., 2001). Various multimedia tools are currently used by many instructors to communicate difficult topics and concepts to their students in meaningful ways. One area of multimedia showing rapid development is the animation or visual representation.

Visual representations play a critical role in the communication of science concepts (Ametller \& Pinto, 2002; Mathewson, 1999; Patrick et al., 2005). Numerous studies have focused on the benefit of using visual representations to communicate concepts in the classroom setting (Schnotz \& Kulhavy, 1994; Van Sommeren et al., 1998). In the science classroom, these graphics are especially helpful when representing phenomena that learners cannot observe or experience directly (Buckley, 2000; Hegarty et al., 1991). Since many students depend on their senses to learn, teaching the invisible and abstract concepts in biology would be difficult without visuals. For this reason, visual representations aid in making abstract concepts more concrete. Visual representations also are preferred for displaying multiple relationships and processes that are difficult to describe with text alone.

The concepts of transport across cell membrane i.e. diffusion, osmosis and active transport are very important for biology students for sound understanding of the functioning of the cell. Diffusion is the primary method of short distance transport in cells and cellular systems. Osmosis is used to explain water uptake by plants, turgor pressure in plants, water balance in aquatic creatures and transport in living organisms (Odom, 1995). On the other hand, active transport is the movement of molecules against concentration gradient across membrane which maintains the homeostasis in the body. Unfortunately students find these topics very difficult to understand (Friedler et al., 1987) and several biology education researchers have 
reported student misconceptions associated with these topics (Marek, 1986; Zuckerman, 1994; Odom \& Barrow, 1995). One reason why students may have difficulty with the concepts of diffusion, osmosis and active transport is that these concepts require students to visualize and think about chemical processes at the molecular level (Johnstone \& Mahmoud, 1980; Friedler et al., 1987; Westbrook \& Marek, 1991). Studies have shown that instruction involving computer animations can facilitate the students thinking about chemical processes at the molecular level (Williamson \& Abraham, 1995; Russel et al., 1997; Sanger \& Greenbowe, 1997).

\section{Purpose of Study}

The purpose of this study was to explore the effectiveness of computer animations in promoting understanding of dynamic processes involved in membrane transport i.e. diffusion, osmosis and active transport.

Membrane transport is selected for this study because:

- Diffusion, osmosis and active transport are key to understanding many important life processes.

- Previous studies have indicated biology students have difficulty in learning diffusion, osmosis and active transport and more effective teaching strategies are needed.

\section{Methodology}

A total of 62 pre-service teacher trainees enrolled in B. Sc. B. Ed. Part-I biological science of Regional Institute of Education, Bhubaneswar formed the sample for the study. They were randomly segregated into two groups: the control group (30 trainees) and experimental; group (32 trainees). A test was conducted to verify the comparability of knowledge on membrane transport of the two groups. The control group trainees were exposed to the content through conventional teaching methods, using a teacher centered strategy or lecture method involving "chalk and talk". The trainees of experimental group were taught in the same traditional lecture format but integrated with computer animation activities.

Four research instruments were used in this study: 1) a closed form questionnaire in the form of statements designed and used to examine the ideas on membrane transport. Trainees were asked to respond by ticking boxes labeled "Agree", "No idea" and "Disagree". There are fifteen statements in the questionnaire of which eight are scientifically acceptable and seven are scientifically unorthodox interspersed at random, 2) a multiple choice written questionnaire (MCQ) containing twenty questions with four possible answers for each question (a-d), 3) an open ended written questionnaire (OEQ) containing ten questions and 4) another open ended questionnaire of three questions used for personal interview.

Trainees were asked to answer the open ended questionnaire first and after that multiple choice and statement based closed form questionnaires were given. Multiple choice and open ended questionnaires were used for both pre-test i.e. before teaching and post-test i.e. after teaching for both control and experimental groups. The questions in the MCQ and OEQ were grouped under two main categories:

1) Questions dealing with the structure of cell membrane.

2) Questions dealing with the molecular processes of diffusion, osmosis and active transport.

\section{Results}

\section{Response to Statement Based Closed Form Questionnaire}

The pre-service teacher trainees' ideas on cell membrane and membrane transport are shown in Figures 1 and 2. About twothird trainees (68\%) affirmed that in cell membrane phospholipid molecules are arranged in two layers and proteins are embedded in a discontinuous mosaic pattern and four-fifth (79\%) were confident about the occurrence of diffusion in all three states of matter. However, majority of the trainees were not knowing that charged and polar solutes move across the membrane with the help of channel or transporter proteins (68\%) that transporter proteins involved in facilitated diffusion undergo conformational change upon binding of solute to it, thus exposing the solute to the other side of the membrane (62\%), that potential energy stored in ionic gradients is utilized by a cell to transport another solute from its lower concentration to higher concentration (77\%), and that diffusion takes place in both direction (63\%). Surprisingly, only half of the trainees correctly believed that active transport helps in generating steep concentration gradient of ions across cell membrane (52\%) and that water moves readily through a semipermeable membrane

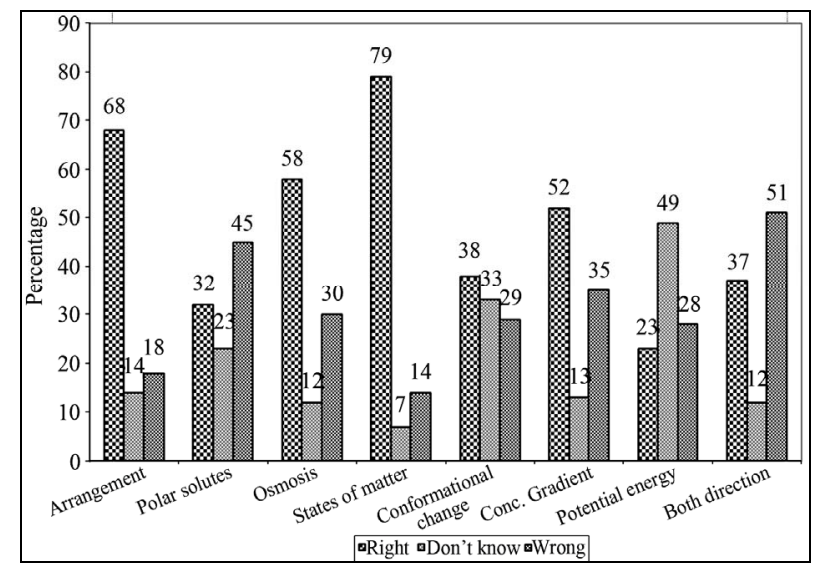

Figure 1.

Trainees' responses to scientifically acceptable statements on membrane transport.

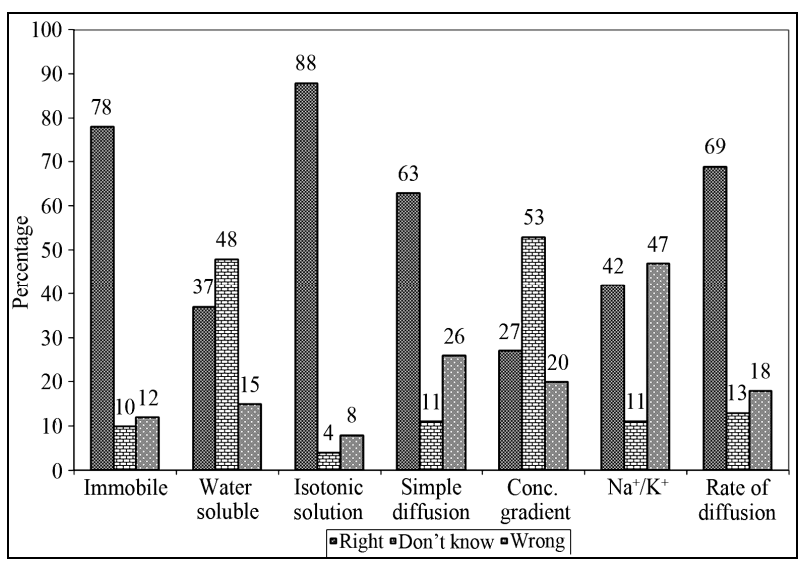

Figure 2.

Trainees' responses to scientifically unorthodox statements on membrane transport. 
from a region of lower solute concentration to a region of higher solute concentration (58\%).

Majority of the trainees showed very low level of understanding about membrane transport. They thought that phospholipid molecules in the membrane are immobile (88\%), that a cell placed in an isotonic solution maintains a constant volume as no water movement occurs (92\%), that ATP energy is required for facilitated diffusion (74\%), that rate of diffusion is inversely proportional to the temperature of the medium and directly proportional to the molecular weight of the diffusing molecules (82\%), that lipid bilayer allows random movement of water soluble materials into and out of the cell (85\%), and that $\mathrm{Na}^{+} / \mathrm{K}^{+}$ion exchange pumps maintain high concentration of $\mathrm{K}^{+}$ ions outside and $\mathrm{Na}^{+}$ions inside of the cell (53\%). Maximum trainees could not differentiate between concentration gradient and electrochemical gradient (80\%).

\section{Results of Pre-Test and Post-Test of Multiple Choice and Open-Ended Questionnaires}

In the pre-test, the average score was 28.7 for control group and 29.2 for experimental groups in the multiple choice questionnaires, while mean score for open-ended questionnaire was 23.8 and 25.2 for control group and experimental group respectively. Comparison of results of pre-test revealed that there is no significant difference amongst the trainees of control and experimental groups. Therefore, the two groups could be treated as comparable groups.

The results of the post-test for multiple choice questionnaires are shown in Figure 3. The average score was higher (88.6) for experimental group than the control group (63.4). Analysis of trainees' answers to the open-ended questionnaire showed similarity to the findings from the multiple choice questionnaires, the average score of the experimental group was 83.7 differed significantly from that of the control group i.e. 57.3 (Figure 4). The post-test results clearly indicated that the trainees of the experimental group have developed better understanding of the membrane transport than the trainees of the control group.

\section{Analysis of Sub-Topics}

As mentioned in the methodology, the questions in both multiple choice and open-ended questionnaires could be grouped under two categories of subtopics:

1) Structure of cell membrane.

2) Molecular processes of diffusion, osmosis and active transport.

Comparable scores regarding the multiple choice questions and open-ended questions for both categories of trainees are shown in Figures 5 and 6.

1) Structure of cell membrane. A total of eight questions in the two questionnaires (five in multiple choice questionnaire and three in open-ended questionnaire) were grouped under this subtopic. These questions focused on the arrangement of lipids and proteins in the membrane and their nature. Inspection of the average scores of the multiple choice questions (Figure 5) concerning this subtopic showed that the average scores of trainees of experimental group was 23.4 while that of trainees of control group was 19.1. The same pattern occurred with the scores of the open-ended questions of this subtopic (Figure 5) in which trainees of the experimental group scored (26.2) higher than the trainees of control group (18.6).

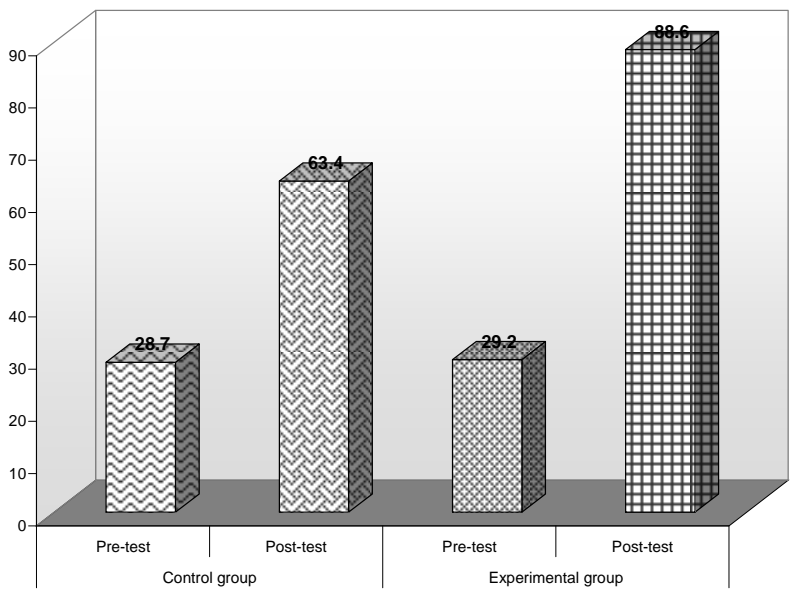

Figure 3.

Average scores of the pre-test and post-test for the multiple choice questionnaire.

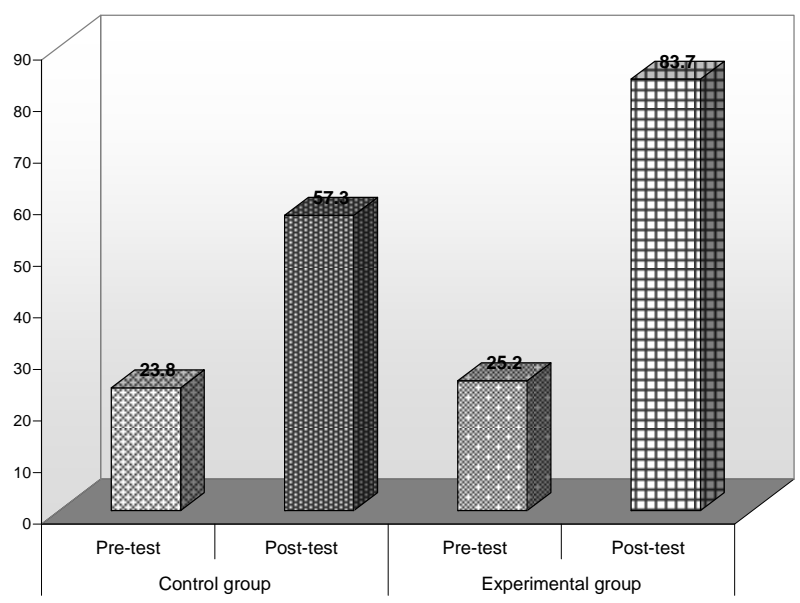

Figure 4.

Average scores of the pre-test and post-test for the open-ended questionnaire.

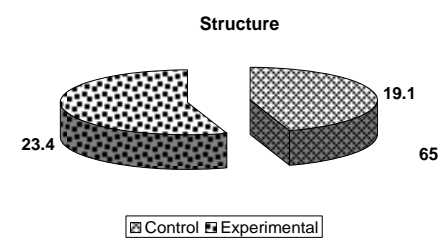

(a)

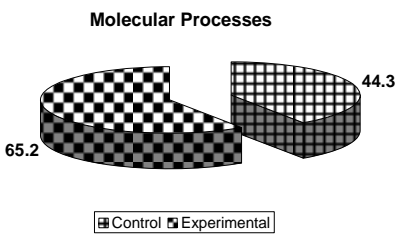

(b)
Figure 5.

Average scores for questions related to subtopic (a) and subtopic (b) of the multiple choice questionnaire.

2) Molecular processes of diffusion, osmosis and active transport. A total twenty two questions in the two questionnaires were concerned with the molecular processes of membrane transport. Inspection of the average scores in the multiple choice questions (Figure 6) dealing with molecular processes showed a similar pattern to the one found in the first subtopic: the average scores of the experimental group (65.2) was significantly higher than the average scores for the control group (44.3). Results of open-ended questions also revealed similar significant difference amongst the trainees of experimental 


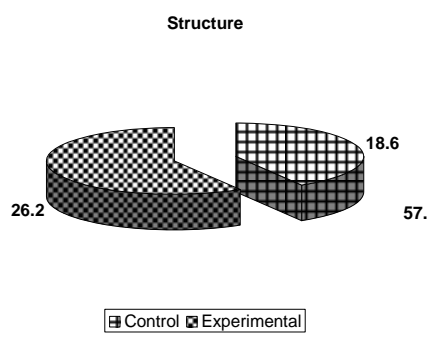

(a)

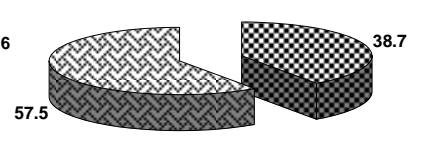

\section{ⓒontrol వExperimental}

(b)
Figure 6.

Average scores for questions related to subtopic (a) and subtopic (b) of the multiple choice questionnaire.

group (57.5) and control group (38.7).

A summary of the findings concerning the two subtopics showed that the average scores of open-ended questions were lower than the multiple choice questions, for both groups. It seems that it was easier for trainees to choose correct answer to the multiple choice questions than to articulate correct responses to the open-ended questions.

\section{Personal Interviews of Trainees of Experimental Group}

In the individual interviews, when trainees of experimental group were asked: Did the integration of computer animations help you in achieving better understanding of the membrane transport? All the trainees gave a positive answer and showed high level of confidence and satisfaction. We could visualize the exact arrangement of phospholipids, cholesterols and proteins in the membrane and the movement of phospholipid molecules. One trainee said: I was not clear during my board examination that how the molecules pass through tightly packed phospholipids bilayer and through the protein channels. Now it is very clear to me because of animation activities. Another trainee said: I was taught and also written in the book that the transporter proteins in the membrane undergo conformational change during transport of molecules. I was unable to imagine what this conformational change is but now I am clear. Most of the interviewees said: We could visualize the exact mechanism of $\mathrm{Na}^{+} / \mathrm{K}^{+}$ion exchange pumps and differences between primary and secondary active transport. Another interview question was: Do you think membrane transport is a difficult topic? No, said almost all interviewees.

The findings that were gathered through the multiple choice questionnaire, open-ended questionnaire and individual interviews indicated that integration of computer animations in the instruction of membrane transport could enhance trainees' achievement of experimental group.

\section{Discussion}

A basic understanding of the functioning of cell membrane is essential for a sound understanding of the functioning of cell in living organisms. The pre-test results of the present study clearly showed poor understanding of the processes of membrane transport indicated by several misconceptions prevailing in the mind of pre-service teacher trainees. Majority of the trainees thought that phospholipid molecules do not exhibit any movement, that volume of a cell remains unchanged when placed in an isotonic solution because of no movement of water across the membrane, that ATP energy is required for facilitated diffusion, that rate of diffusion is inversely proportional to the temperature of the medium and directly proportional to the molecular weight of the diffusing molecules, that water soluble substances can pass through lipid bilayer and that $\mathrm{Na}^{+} / \mathrm{K}^{+}$ion exchange pumps maintain high concentration of $\mathrm{Na}^{+}$inside of the cell and high $\mathrm{K}^{+}$ion concentration outside of the cell. It seems membrane transport topic is very difficult to understand (Friedler et al., 1987; Sanger et al., 2001) and several biology education researchers have reported student misconceptions associated with this topic (Marek, 1986; Zuckerman, 1994; Odom \& Barrow, 1995).

Investigations have revealed quite a number of reasons: one is that some biology concepts are very difficult for teachers to teach as well as for students to learn (Ige, 2001; Nzewi \& Osisioma, 1994; Okebukola, 1990; Orukotan, 1999). Several studies have reported that this difficulty is due to abstract nature of the concepts and the processes involved are not physically observable (Abimbola, 1998; Locke \& McDermid, 2005; Richards \& Ponder, 1996; Snowden \& Green, 1994; Turney, 1995). Hence for better understanding of the concepts of membrane transport, visualization of chemical processes at molecular level is required (Johnstone \& Mahmoud, 1980; Friedler et al., 1987; Westerbrook \& Marek, 1991).

From the post-test result of the present study, it was observed that more trainees of the control group believed that in the processes of diffusion, particles move until equilibrium is reached and then stop moving (item 20 of MCQ) than the experimental group (65\% versus $12.5 \%$ ). Similarly, majority of the trainees in the control group (90\%) believed that there would be no change in volume of RBCs when placed in an isotonic solution as there would be no flow of water molecules in any direction (item 8 in the MCQ) while trainees of experimental group $(81.2 \%)$ who viewed the animations correctly stated that flow of water molecules in both direction is equal and there would be no net gain or loss. In general, it appears that these animations were successful in helping trainees understand the dynamic nature of equilibrium processes which is a common and persistent misconception exhibited by students in chemistry classes as well (Gorodetsky \& Gussarsky, 1986). Misconceptions are very important during the learning processes of individuals. It is well known that it is not easy to eliminate the misconceptions at least by employing traditional instructional methods (Yenilmez \& Tekkaya, 2006). One of the alternative ways of overcoming this problem may be using computer assistant materials in biology classrooms. In the present study, computer animations provided better learning environments for trainees to understand membrane transport with respect to control group.

The data analysis of the present study showed that the average score (88.6) of the experimental group was significantly higher $(p<.01)$ than the mean score (63.4) of the control group in the multiple choice questions. Similarly, in case of openended questions, the average score (83.7) of experimental group was higher $(p<.01)$ than the average score $(57.3)$ of control group. Analysis of the mean scores according to subtopics showed that for both subtopics, the experimental group outscored the control group. It is noteworthy, that in the second subtopic, i.e. molecular processes of diffusion, osmosis and active transport, the average scores were comparatively low, both for control group (44.3 for MCQ and 38.7 for OEQ) and experimental group (65.2 for MCQ and 57.5 for OEQ) in com- 
parison to the average scores of control group (19.1 for MCQ and 18.6) and experimental group (23.4 for MCQ and 26.2 for OEQ) for first subtopic i.e. structural organization of the cell membrane. This shows that the process part is harder for students to understand than the structural part. Nevertheless, here too, the computer animations significantly increased trainees' understanding. As mentioned in the introduction, researchers suggested that dynamic computer animation can be used to give an accurate and rich picture of the dynamic nature of cellular processes, which are often very difficult to understand from text-based presentations of information (Rotbain et al., 2008). Similar findings in life sciences have also been reported by Stitch (2004), Mcclean et al. (2005) and O’Day (2006). Stitch (2004) carried out a study in which, after a lecture on apoptosis, one group of 31 students who viewed an animation on apoptosis was compared to a group of 27 students who did not. While the students who saw the animation obtained significantly higher test scores than those who didn't, it can't be ruled out that the extra few minutes of exposure to the topic alone could explain, at least in part, the improved grade. McClean et al. (2005) used animations for teaching protein synthesis to one group of students while another group of students were taught without animations. The group viewing the animations obtained significantly higher test scores than the group that didn't. Williamson and Abraham (1995), who explored the effect of animations on college chemistry students, found that instruction with animations may increase conceptual understanding by promoting the formation of dynamic mental models of the particulate nature of matter. In this type of instruction, animation provided more scientifically correct visual models for submicroscopic processes.

In the individual interviews, trainees reported on three major advantages of using computer animations. The first one is that the animation activities helped the students to visualize the abstract concepts and processes of membrane transport by representing the topic in a concrete manner. Trainees said: "The computer animations helped us very much. It demonstrated the process, since we can't really see it. It was like we could see it in front of our eyes and visualize the processes". The second advantage that trainees raised was how this enables them to work individually in their own time, to run the animation over and over as much as they needed. Trainees commented: "it helped me more than the lesson in the class, since I could run it over and over as many times as I wanted”. Another advantage trainees mentioned was the contribution of the activities to the diversification of the lessons. Trainees said that the animation activities "broke the routine" of the traditional lecture format. They said that they enjoyed the activity very much and would like to have such activities in other biology topics too. Similar feed back of students have also been reported by Rotbain et al. (2008) in their study while teaching molecular biology by using computer animation.

The findings of the present study concerning the advantages of animation activities over the traditional lecture method in terms of learning the dynamic process accord with Schnotz and Kulhavy (1994), Van Sommeren et al. (1998), Mathewson (1999), Ametller and Pinto (2002), Kozma (2003) and Marbach-Ad et al. (2008). An effective teaching makes student more aware of their own knowledge and cognitive processes, as well as aware of how compatible these processes were with a given learning situation. Integration of computer animations appeared to allow trainees to achieve this, compared with being passive recipients of information as in lectures.

\section{Conclusion}

Based on the results of this study, it is recommended that the use of computer animation, a type of instructional strategy that is capable of transforming students from passive receptacles of information into active learners, should be used to teach biology and other science subjects. Teachers are exposed to new and emerging techniques that are relevant for the class room and can motivate students, and thereby increase their achievement.

\section{REFERENCES}

Abimbola, I. O. (1998). Teachers' perceptions of important and difficult biology content. Journal of Functional Education, 1, 10-12.

Ametller, J., \& Pinto, R. (2002). Students' reading of innovative images of energy at secondary school level. International Journal Science Education, 24, 285-312. http://dx.doi.org/10.1080/09500690110078914

Barnett, L., Brunner, D., Maier, P., \& Warren, A. (1996). Technology in teaching and learning: A guide for academics. Eastleigh: Greentree press.

Buckley, B. C. (2000) Interactive multimedia and model-based learning in biology. International Journal of Science Education, 22, 895-935. http://dx.doi.org/10.1080/095006900416848

Friedler. Y., Amir, R., \& Tamir, P. (1987). High school students' difficulties in understanding osmosis. International Journal of Science Education, 9, 541-551. http://dx.doi.org/10.1080/0950069870090504

Gorodetsky, M., \& Gussarsky, E. (1986). Misconceptualization of the chemical equilibrium concept as revealed by different evaluation methods. European Journal of Science Education, 8, 427-441. http://dx.doi.org/10.1080/0140528860080409

Hegarty, M., Carpenter, P. A., \& Just, M. A. (1991). Diagrams in the comprehension of scientific text. In R. Barr, M. L. Kamil, P. B. Mosenthal, \& P. D. Pearson (Eds.), Handbook of reading research: Volume 2 (pp. 641-668). New York: Longman.

Ige, T. A. (2001). Concept mapping and problem solving teaching strategies as determinants of achievement in senior secondary ecology. Ibadan Journal of Educational Studies, 1, 290-301.

Johnstone, A. H., \& Mahmond, N. A. (1980). Isolating topics of high perceived difficulty in school biology. Journal of Biological Education, 14, 163-166.

http://dx.doi.org/10.1080/00219266.1980.10668983

Kozma, R. (2003). The material features of multiple representations and their cognitive and social affordances for science learning. Learning and Instruction, 13, 205-226. http://dx.doi.org/10.1016/S0959-4752(02)00021-X

Locke, J., \& McDermid, H. E. (2005). Using pool noodles to teach mitosis and meiosis. Genetics, 170, 5-6. http://dx.doi.org/10.1534/genetics.104.032060

Marbach-Ad, G., Rotbain, Y., \& Stavy, R. (2008). Using computer animation and illustration activities to improve high school students' achievement in molecular genetics. Journal of Research in Science Teaching, 45, 273-292. http://dx.doi.org/10.1002/tea.20222

Marek, E. (1986). Understandings and misunderstandings of biology concepts. The American Biology Teacher, 48, 37-40. http://dx.doi.org/10.2307/4448184

Mathewson, J. H. (1999). Visual-spatial thinking: An aspect of science overlooked by educators. Science Education, 83, 33-54. http://dx.doi.org/10.1002/(SICI)1098-237X(199901)83:1<33::AID-S CE2>3.0.CO;2-Z

McClean, P., Johnson, C., Rogers, R., Daniels, L., Reber, J., Slator, B. M., Terpstra, J., \& White, A. (2005). Molecular and cellular biology animations: Development and impact on student learning. Cell Biology Education, 4, 169-179. http://dx.doi.org/10.1187/cbe.04-07-0047

Nzewi, U., \& Osisioma, N. U. I. (1994). The relationship between formal reasoning ability, acquisition of science process skills and science achievement. Journal of the Science Teachers' Association of 


\section{A. K. MOHAPATRA}

Nigeria, 29, 4-49.

O’Day, D. H. (2006). Animated cell biology: A quick and easy method for making effective high quality teaching animations. CBE: Life Sciences Education, 5, 155-163.

http://dx.doi.org/10.1187/cbe.05-11-0122

Odom, A. L. (1995). Secondary and college biology students' misconceptions about diffusion and osmosis. The American Biology Teacher, 57, 409-415. http://dx.doi.org/10.2307/4450030

Odom, A. L., \& Barrow, L. H. (1995). Development and application of a two-tire diagnostic test measuring college biology students' understanding of diffusion and osmosis after a course of instruction. Journal of research in Science Teaching, 32, 45-61. http://dx.doi.org/10.1002/tea.3660320106

O’Hagan, C. (1997). SEDA Special 4: Using educational media to improve communication and learning. Birmingham: SEDA.

Okebukola, P. A. O. (1990). Attaining meaningful learning of concepts in genetics and ecology. An examination of the potency of the concept mapping technique. Journal of Research in Science Teaching, 27, 493-504. http://dx.doi.org/10.1002/tea.3660270508

Orukotan, A. F. (1999). The relative effect at instructional strategies of framing and rehearsal on senior secondary school students learning outcomes in some biology topics. Doctoral Dissertation, Ibadan: University of Ibadan.

Patrick, M. D., Carter, G., \& Wiebe, E. N. (2005). Visual representations of DNA replication: Middle grades students' perceptions and interpretations. Journal of Science Education and Technology, 14, 353-365. http://dx.doi.org/10.1007/s10956-005-7200-6

Ramsden, P. (1996). Learning to teach in higher education. London: Routledge.

Richards, M. P., \& Ponder, M. (1996). Lay understanding of genetics a test of a hypothesis. Journal of Medical Genetics, 33, 1032-1036. http://dx.doi.org/10.1136/jmg.33.12.1032

Rotbain, Y., Marbach-Ad, G., \& Stavy, R. (2008). Using a computer animation to teach high school molecular biology. Journal of Science education and Technology, 17, 49-58. http://dx.doi.org/10.1007/s10956-007-9080-4

Russel, J. W., Kozma, R. B., Jones, T., Wykoff, J., Marx, N., \& Davis, J. (1997). Use of simultaneous-synchronized macroscopic, microscopic, and symbolic representations to enhance the teaching and learning of chemical concepts. Journal of Chemical Education, 74, 330-334. http://dx.doi.org/10.1021/ed074p330

Sanger, M. J., \& Greenbowe, T. J. (1997). Students' misconceptions in electrochemistry: Current flow in electrolyte solutions and the salt bridge. Journal of Chemical Education, 74, 819-823. http://dx.doi.org/10.1021/ed074p819

Sanger, M. J., Brecheisen, D. M., \& Hynek, B. M. (2001). Can computer animations affect college biology students' conceptions about diffusion and osmosis? The American Biology Teacher, 63, 104-109. http://dx.doi.org/10.1662/0002-7685(2001)063[0104:CCAACB]2.0. $\mathrm{CO} ; 2$

Schnotz, W., \& Kulhavy, R. W. (1994). Comprehension of graphics. Amsterdam: Elsevier Publishers.

Sneddon, J., Settle, C., \& Triggs, G. (2001). The effects of multimedia delivery and continual assessment on student academic performance on a level 1 undergraduate plant science module. Journal of Biological Education, 36, 6-10. http://dx.doi.org/10.1080/00219266.2001.9655788

Snowden, C., \& Green, J. (1994). New reproductive technologies attitudes and experiences of carrier of recessive disorders. Unpublished Report, Cambridge: University of Cambridge: Centre for Family Research.

Stith, B. J. (2004). Use of animation in teaching cell biology. Cell Biology Education, 3, 181-188. http://dx.doi.org/10.1187/cbe.03-10-0018

Turney, J. (1995). The public understanding genetics: Where next? European Journal of Genetics Society, 1, 5-20.

Van Sommeren, M., Reimann, P., Boshuizen, H., \& De Jong, T. D. (1998). Learning with multiple representations. Amsterdam: Permagon.

Westbrook, S. L., \& Marek, E. A. (1991). A cross-age study of student understanding of the concept of diffusion. Journal of Research in Science Teaching, 28, 649-660. http://dx.doi.org/10.1002/tea.3660280803

Williamson, V. M., \& Abraham, M. R. (1995). The effects of computer animations on the particulate mental models of college chemistry students. Journal of Research in Science Teaching, 32, 522-534. http://dx.doi.org/10.1002/tea.3660320508

Yenilmez, A., \& Tekkaya, C. (2006). Enhancing students' understanding of photosynthesis and respiration in plant through conceptual change approach. Journal of Science Education and Technology, 15, 81-87. http://dx.doi.org/10.1007/s10956-006-0358-8

Zuckerman, J. T. (1994). Problem solvers' conceptions about osmosis. The American Biology Teacher, 56, 22-25. http://dx.doi.org/10.2307/4449737 